\begin{tabular}{|c|l|}
\hline Title & Territorial capital, smart tourism specialization and sustainable regional development : Experiences from Europe \\
\hline Author(s) & Romao, Joao; Neuts, Bart \\
\hline Citation & $\begin{array}{l}\text { Habitat International, 68, 64.74 } \\
\text { https://doi.org/10.1016j.habitatint.2017.04.006 }\end{array}$ \\
\hline Issue Date & 2017-10 \\
\hline Doc URL & http://hdl.handle.net/2115/75690 \\
\hline Type & article (author version) \\
\hline File Information & romao_habitat.pdf \\
\hline
\end{tabular}

Instructions for use 


\title{
Territorial capital, smart tourism specialization and sustainable regional development: experiences from Europe
}

João Romão (Centre for Advanced Studies in Management and Economics, University of Algarve)

Bart Neuts (School of Hospitality \& Tourism; Auckland University of Technology)

\begin{abstract}
This study analyses the contribution of territorial sensitive resources related to natural and cultural features (environmental dimension), innovation capabilities and specialization patterns (smart specialization) to regional sustainable development (spatial sustainability). In the context of a fast and continuous expansion of tourism activities, particular attention is given to their impacts. The results of our path model suggest that different patterns of tourism dynamics coexist in European regions and that, for those where this sector assumes larger socio-economic importance, the contribution to the achievement of the "Millennium Goals", as proposed by the United Nations, is relatively poor. Regions particularly endowed in natural resources reveal a weak socio-economic performance, while showing high levels of specialization in tourism, based on large scale and low value-added products and services, suggesting that new approaches to territorial design are required. This also leads to important spatial unbalances, with the most tourism-dependent European regions revealing relatively low levels of regional gross domestic product and high levels of unemployment. Despite their relatively good performance in terms of CO2-emissions, it seems important for those regions' sustainable development to increase the value added in tourism, by reinforcing the linkages with other relevant regional economic sectors. Information and communication technologies can contribute to these achievements, through the integration of knowledge and innovations into the products and services comprising the smart tourism experiences (smart development) and their connections with related sectors (smart specialisation).
\end{abstract}

\section{Keywords:}

Territorial capital, sustainability, smart tourism, innovation, regional development, path model

This document corresponds to the manuscript accepted for publication as:

Romão, J., Neuts, B. (2017) Smart tourism, territorial capital, and sustainable regional development: experiences from Europe. Habitat International, 68: 64-74

DOI: $10.1016 /$ j.habitatint.2017.04.006 


\section{Territorial capital, smart tourism specialization and sustainable regional development: experiences}

\section{from Europe}

\section{Introduction}

The regional cohesion policy within the European Union consists of significant funding instruments aimed at removing disparities between regions and improving general economic well-being. As stated by Alexiadis (2017), this type of public policy should be aimed at helping territories to make best use of their territorial assets, in order to increase competitiveness and prosperity in a globalizing world. Concurrently, regional growth needs to take place within a sustainable development framework, which clearly underpins the Commission's regional policy targets: employment, research and development, climate change and energy sustainability, education, and fighting poverty and social exclusion (Directorate-General for Regional and Urban Policy, 2016). The focus on the importance of local territorial resources was recently reinforced with the introduction of the concept of smart specialization (Foray et al., 2012) as a core element of the regional innovation strategies.

Serbanica and Constantin (2017) mention significant socio-economic regional disparities and urbanrural gaps within the European Union, necessitating specific attention for rural areas and second-tier cities. Within the context of particular territorial assets and competitive strengths, tourism is seen as a potential driver to reduce the urban-rural gap (as analysed for the Chinese regions by Liu et al., 2017) and a key strategic sector for development via the European Structural and Investment Funds. Particularly within the less developed regions there is potential for tourism-led growth, due to its spill-over and job creation potential and low barriers to market entry (Directorate-General for Regional and Urban Policy, 2016). The relevance of tourism as driver for world trade, prosperity, and poverty alleviation, specifically in the least developed countries with limited alternative strategic development options is similarly recognized by the World Tourism Organization (2010).

The unprecedented socio-economic importance of tourism is clearly expressed by the high number of international arrivals registered worldwide in 2015 (almost 1200 million) with more than half of them taking place in Europe (World Tourism Organization, 2017). While tourism can therefore offer opportunities for regional development based on territorial resources, at the same time, it is recognized that tourism impacts on the utilization of these resources and the organization of economic systems can negatively contribute to the sustainability of a destination as well. This could potentially lead to a vicious circle in which regional amenities attract visitors only to then be negatively affected by tourism. The recent development and generalization of digital technologies and their broad applications in many aspects of our daily life can provide opportunities to manage such potential negative effects on destination sustainability. On the $1^{\text {st }}$ UNWTO World Conference on Smart Destinations in February, 2017, the organization stated how smart destinations are key to sustainable development, specifically in terms of measurement and evidence-based decision making, prioritization and anticipation towards the future. The concepts of "smartness" emerged in 
the literature, both at the urban scale - the smart city (Kourtit et al., 2012; Caragliu and Del Bo, 2012) - or at the regional level - like the "smart specialization" (Foray et al., 2012; McCann \& Ortega-Argilés, 2015) enlarging the scope of sustainable development, mostly through the incorporation of aspects related to the importance of innovation, creativity, information, communication and interaction. As Borseková et al. (2016) mention, smart specialization via spatial competitive advantage needs innovations grounded in social, cultural and institutional contexts.

This paper combines the concepts of sustainable development and smart specialization via an analysis of the utilization of territorial sensitive resources. By focusing on the particular case of tourism development and specialization (an environmental approach, focused on the management of natural and cultural resources), the question is levied as to whether competitive advantages in terms of tourism characteristics lead to regional sustainable development. Regional innovation dynamics are taken into consideration by framing the discussion within the concept of smart specialization. The primary research objective is to establish whether territorial resources, innovation dynamics and tourist performance and specialization contribute or detracts to sustainable regional development goals within various European regions. Specifically, the paper considers the recently defined Millennium Goals (United Nations, 2015), as a set of universal achievements for contemporary societies in terms of sustainable development, and the role that tourism is expected to play within this context (UNWTO, 2015). Despite the abundance of studies on the economic impacts of tourism on regional development, on the effects of tourism dynamics on poverty alleviation in less developed countries and regions or on the environmental consequences of tourism activities (both on natural areas or urban contexts), there are very few attempts to simultaneously analyse the overall impacts of tourism on the three main pillars of sustainable development, contextualized by the regional specialization patters and innovation dynamics, defining the contemporary processes of smart development.

In what follows, the paper first introduces the theoretical framework by describing how the concepts of sustainable use of resources, smart development or sustainable development have been applied in tourism studies, with their implications for territorial design and spatial unbalances. In Section 3 the methodology is presented, leading to an analysis of 252 NUTS 2 European regions. Section 4 shows the main modelling results. Finally, Section 5 discusses the results within a wider context and Section 6 summarizes the main findings, taking into account the concepts of smart specialization and spatial imbalances observed in European regions regarding their processes of sustainable development.

\section{Theoretical framework}

The analysis and discussion of the role of territorial resources (both material - related to natural and cultural assets - and immaterial - related to innovation capabilities), within the context of raising importance of tourism within the regional economies (and its influence on sustainable regional development) requires an understanding of the competitiveness of tourism regions. Ritchie \& Crouch (2003) developed a comprehensive model on destination competitiveness, starting from a basis of core resources and attractors such as climate, culture and history, entertainment - and supporting factors and resources - such as 
infrastructure, accessibility, hospitality. Through concentrated efforts in destination management and supporting institutional structures for terms of destination policy planning and development, and within the limits of amplifying determinants (such as safety, awareness/image and carrying capacities), a superior competitive position might be established. Comparative advantages between regions depend on physical resources, human resources, capital resources, historical and cultural resources, infrastructure, and general size of the economy. The latter relate to aspects of territorial capital and identify regional elements that could be framed by a "smart specialization" approach (Foray et al., 2012), with a specific tourism focus.

Several authors emphasized the importance of the linkage between the uniqueness of territorial resources and the differentiation of tourism supply, in order to generate high quality tourism products and services, while ensuring the preservation of resources (e.g. Kozak, 1999; Buhalis, 1999; Hassan, 2000; Page \& Dowling; 2002). Particularly focusing on cultural assets in urban contexts, Zhang et al. (2015) critically discuss the relation between tourism oriented management of world heritage sites and community involvement, while Al Haija (2011) offers a similar discussion within a larger geographical scope (the "historical towns). Domicelj (1992), in turn, looks at the relations between "experiential tourism" and cultural development, and its implications for planning processes.

Smart specialization guides the regional innovation strategies under development in European regions, despite its recent (and questionable) theoretical formulation (see, e.g., Boschma, 2016, for a concise discussion). This approach emphasizes the importance of endogenous resources and the development of inter-sectorial relations between related sectors (related variety), in order to generate spillover effects of innovation processes, while emphasizing the importance of "key-enabling technologies" and information and communication technologies as core strategic elements that can boost the development of the priority sectors of each region. This is also in line with Poon's (1994) central thesis that innovation and differentiation are more important than low cost advantages to increase competitiveness.

In this sense, the concept of smart specialization seems to be in accordance with the definition of smart cities (or regions) proposed by Caragliu et al. (2011, p. 50): "A city [region] is smart when investments in human and social capital and traditional (transport) and modern (ICT) communication infrastructure fuel sustainable economic growth and a high quality of life, with a wise management of natural resources, through participatory governance". This definition integrates the role of innovation and digital technologies on the sustainable development approach.

As noted by Boes et al. (2016), the concept of "smart tourism" also stresses the potential role of digital technologies in the development of collaborative processes between rival service providers at the destination level ("coopetition") or for the co-creation of destinations and experiences (through the increasing interaction between producers and consumers), benefiting from some particular characteristics of tourism services (interoperability, spatiality and temporality, implying direct interaction between suppliers and consumers, in the same place, at the same time). Along with their implications on the territorial planning of spaces, infrastructure and services (Binkhorst \& Den Dekker, 2009; Kim \& Fesenmaier, 2015), these characteristics seem to provide a solid basis for the development of place and knowledge-based innovation strategies, relying on the specific resources, knowledge, and information available in each region. In 
accordance with the principles of sustainable development and smart specialization, these authors also stress the importance of participatory processes of governance at the destination level.

While discussing possible processes of territorial management and design in order to promote processes of sustainable development, recent works analysed the possible connections between natural resources, economic growth and social benefits (e.g. Redclift \& Woodgate, 2013), in particular for the case of Europe (Maes \& Jacobs, 2017). Also with important implications for the tourism sector, similar efforts have been made in order to integrate culture and heritage into sustainable development strategies (e.g. Bertacchini \& Segre, 2016; Wu et al., 2016). In a broader sense, the linkage between innovation processes and the principles of sustainable development has been recently addressed by authors like Halme \& Korpela (2014) or França et al. (2017).

UNWTO (2015) emphasized the role of tourism within the 17 goals and 169 targets defined in the “2030 Agenda for Sustainable Development” (United Nations, 2015). In particular, it is proposed that tourism should play an important role in terms of goals 8 (inclusive and sustainable economic growth), 12 (sustainable consumption and production) and 14 (sustainable use of oceans and marine resources), clearly emphasizing the potential impacts of tourism on the development of destination territories and host communities, along with the importance of the protection and preservation of resources. This approach seems to be in accordance with the definition of tourism competitiveness proposed by Ritchie \& Crouch (2003), integrating the concepts of growth, benefits for the host communities and preservation of resources, also with the concerns expressed by Butler (1999), when clarifying the double approach to the concept of sustainability within tourism studies: the protection (sustainable use) of tourism resources and the impacts of tourism on sustainable development. This double approach is a central and innovative aspect of our analysis.

Economic impacts have been broadly analysed during the last decades (e.g. Pablo-Romero \& Molina, 2013), first from an optimistic point of view, related to the "tourism-led growth hypothesis" (an overview is provided by Shubert \& Brida, 2011), which seemed to be confirmed, in different parts of the world, by authors like Chen \& Chiou-Wei (2009), Cortes-Jimenes \& Pulina (2010), Dritsakis $(2004,2012)$ or Nowak, Sahli \& Cortés-Jiménez (2007). More recently, ambiguous results have been found (Lee \& Chang, 2008; Tang \& Jang, 2009; Chou, 2013), or even negative effects of long-term tourism development have been identified, through the transformations within the regional economic structures related to deindustrialization processes (Sheng \& Tsui , 2009; Adamou \& Clerides, 2009; Capó et al., 2007; Romão et al., 2016). Antonakakis et al. (2015) suggest that the economic impacts of tourism on economic growth are time dependent, varying according to the evolution of the destinations.

Questions related to the impacts of tourism on the sustainable use of territorial resources, both in natural areas (related to the preservation of ecosystems, congestion or transformations in the land use) and urban sites (related to the preservation of material and immaterial heritage, congestion, inflation or gentrification) have received broad attention over the last 30 years. Williams \& Ponsford (2009) define the double process of exploitation and protection of resources as the "environmental paradox" (tourism supply relies on the exploitation of assets that must be preserved). Weaver (2006) or Miller and Twining-Ward (2005) proposed comprehensive and systematic approaches to these questions, including discussions related to their 
measurement and possible indicators. More recently, the problems raised by climate change, with higher impacts on coastal areas, reinforced the importance of the environmental aspects within tourism studies, as witnessed by authors like Weaver (2011).

Regarding the social dimension of sustainable development, the potential contributions of tourism for poverty alleviation in less developed countries or regions have been broadly studied, as observed by Zhao and Ritchie (2007), who provide an integrated view of this question. Less attention has been paid to the social implications of tourism development in developed economies, as it is the purpose of this work, focused on European regions, which are generally classified among the most developed at the global level. One example of the importance of this question is the recent work by Milio (2014), identifying the regions with higher levels of specialization in tourism and construction activities as the least resilient (see, e.g., Modica \& Reggiani, 2014, for a definition of this concept) at the European level, facing more difficulties to recover their levels of employment after the negative effects of the international crisis started in 2007.

Based on the ideas of destination competitiveness, sustainable development and smart specialization, this study continues with an integrated analysis (which structure is represented in Figure 1, presented in Section 3.2) of the relations between sensitive territorial resources (cultural and natural assets), the regional tourism dynamics (demand, value added, importance for the regional economy) and other immaterial aspects of the territorial capital (see e.g. Capello et al., 2011) of each region, which seem to be crucial for the three pillars of sustainable development (economic, social and environmental), while framing the results and implications within the smart specialization strategies for European regions, integrating knowledge and technological capabilities.

\section{Methodology}

\subsection{Data collection}

The empirical analysis was based on a secondary data collection for 252 European NUTS 2 regions for the year 2011, corresponding to the scale at which regional development policies are developed and implemented at European level, including the smart specialization strategies, which comprise the regional innovation actions aiming at the mobilization of existing knowledge, technology and human resources. The countries that were represented include Austria, Belgium, Bulgaria, Czech Republic, Denmark, Estonia, Finland, France, Germany, Greece, Hungary, Italy, Latvia, Lithuania, Luxemburg, the Netherlands, Poland, Portugal, Romania, Slovakia, Slovenia, Spain, and the United Kingdom. Analysis on this regional level assists policy-making and management implications since it coincides with the Regional Innovation Strategies (RIS) devised by the European Union for the period 2014-2020.

The information collected from the Eurostat-database comprises indicators of: (a) territorial capital formation, (b) tourism specialization, (c) tourism performance, and (d) sustainable regional development. The regions are therefore characterized in terms of their endowment in cultural and natural resources (the environmental dimension), their tourism dynamics (demand, value added, investment and importance for their specialization patterns) and other immaterial characteristics of their territorial capital (human resources and innovation efforts, as measures of the regional ability to increase its productivity and economic 
performance, defining the preconditions for a smart development process). Territorial capital formation is based on both material and immaterial assets. The former are identified via data on natural resources (measured as the percentage of regional territory protected under Natura 2000), data on cultural assets (measured as the number of UNESCO-classified Cultural Heritage Sites), and data on investment within the tourism sector (measured as the gross fixed capital formation). The latter, immaterial, aspects take the form of human resources (identified as the share of employment with a tertiary education). Data on tourism specialization per region is identified via the share of gross value added (GVA) in tourism within regional gross value added. Secondly, the total employment share in tourism is collected. Identification of tourism performance is expressed by tourism demand (measured as the number of nights in commercial tourism establishments), and total gross value added of tourism.

Finally, sustainable regional development indicators are based on the idea of the triple bottom line. Economic growth is measured as regional gross domestic product (GDP) per inhabitant, at current prices. Variables on the social and environmental dimension of sustainability are more difficult to establish and will be approached via two proxies: the level of regional unemployment, as a measure of social cohesion, and the level of regional $\mathrm{CO} 2$-emissions, as an identifier of environmental conditions. The latter statistic is only available on a national level and was converted to a regional statistic by taking account of the variations in population density. With the exception of natural resources (from the European Commission, DG Environment) and cultural assets (from UNESCO), all data were collected from Eurostat. Table 1 provides an initial summarizing overview of all variables that will be modelled according to the theoretical assumptions. The data for all the variables used in this study are geographically represented in maps presented in the Annex.

Table 1: Variables and data

\begin{tabular}{|c|c|c|c|}
\hline Variable name & Code & Data format & Mean (St. Dev) \\
\hline \multicolumn{4}{|l|}{ Territorial Capital: } \\
\hline Employment share with tertiary education & $E D U C$ & Percentage & $26.016(8.976)$ \\
\hline Natural resources & $N A T$ & Percentage & $14.550(9.651)$ \\
\hline Heritage sites & $H$ & Number of sites & $1.516(1.613)$ \\
\hline Gross fixed capital formation in tourism & $I N V$ & EUR & $1,885.040(2,532.248)$ \\
\hline \multicolumn{4}{|l|}{ Tourism specialization: } \\
\hline Share of GVA in tourism in regional GVA & GVATS & Percentage & $23.732(6.154)$ \\
\hline Share of employment in tourism & EMPTS & Percentage & $23.992(3.9236)$ \\
\hline \multicolumn{4}{|l|}{ Tourism performance: } \\
\hline Tourism demand & $N I G$ & Number of nights & $\begin{array}{l}9,343,839.433 \\
(12,928,287.500)\end{array}$ \\
\hline Gross value added by tourism & GVAT & EUR & $10,229.184(14,029.137)$ \\
\hline \multicolumn{4}{|l|}{ Sustainable regional development: } \\
\hline Regional GDP per capita & $G D P p c$ & $\begin{array}{l}\text { Thousands of } \\
\text { EUR }\end{array}$ & $24.464(15.960)$ \\
\hline Regional unemployment & UNEM & Percentage & $9.212(4.955)$ \\
\hline $\mathrm{CO} 2$-emissions & $E R$ & Millions of tons & $17.701(13.572)$ \\
\hline
\end{tabular}




\subsection{Structural equation modelling}

Figure 1 gives an overview of the hypothesized relationships between the model variables. As can be identified, the model consists of both direct and indirect effects on the three endogenous variables of sustainable regional development (i.e. Regional GDP per capita, Regional unemployment, and CO2emissions).

Hypotheses 1a to 1d relate all aspects of territorial capital to a region's tourism specialization, in accordance with a core concept underlying the smart specialization strategies within the European Union, according to which competitive advantages should rely on regional strengths and existing capabilities - in this case, applied to the tourism sector. Territorial capital refers to both material assets (i.e. Natural resources, Heritage sites, Gross fixed capital formation in tourism) and immaterial assets (i.e. Share of employment with tertiary education). Material assets specifically related to tourist attractiveness are hypothesized to relate positively to regional specialization in tourism (both as the Share of GVA in tourism in the regional GVA, and as the Share of employment in tourism). On the other hand, larger shares of tertiary educated employment might have a negative effect on tourism specialization, since employment in the tourism sector often does not require tertiary diplomas. All of these hypotheses can be written in a collection of simple equations. For instance, the relation between share of employment in tourism (EMPTS) and other model variables is written as:

$$
\text { EMPTS }=\beta_{\text {empts,educ }} E D U C+\beta_{\text {empts,nat }} N A T+\beta_{\text {empts }, h} H+\beta_{\text {empts,inv }} I N V+u
$$

with all $\beta$ 's in the above equation referring to the direct effects of the model paths under H1a-d.

Hypotheses $2 \mathrm{a}$ to $2 \mathrm{~d}$ similarly relate a region's territorial capital to measures of tourism performance (i.e. Tourism demand, GVA by tourism), which can be seen as a measure of an existing resource-based competitive advantage (Hall, 1993). Hypotheses 3a to 3b link the tourism specialization of a region with general tourism performance measures. There seems to be a logical link between employment numbers in tourism and its share in the regional GVA and the overall importance in terms of demand and total GVA. All remaining hypotheses (hypotheses $4 \mathrm{a}$ to $4 \mathrm{~d}, 5 \mathrm{a}$ to $5 \mathrm{~b}$, and $6 \mathrm{a}$ to $6 \mathrm{~b}$ ) relate to effects on the sustainable regional development, combining indicators on the triple bottom line of sustainability. These relationships might serve to confirm Milio's (2014) findings on tourism specialization and resilience, the link with a knowledge-driven smart specialization strategy, and the extent to which sustainable development goals are supported. It therefore offers a wider outlook on tourism's effect on non-economic sustainability indicators. The equation for gross domestic product per capita then becomes:

$$
\begin{aligned}
& G D P p c \\
& =\beta_{g d p, e d u c} E D U C+\beta_{g d p, n a t} N A T+\beta_{g d p, h} H+\beta_{g d p, i n v} I N V+\beta_{g d p, e m p t s} E M P T S \\
& +\beta_{g d p, \text { gvats }} G V A T S+\beta_{g d p, n i g} N I G+\beta_{g d p, g v a t} G V A T+w
\end{aligned}
$$

with the $\beta$ 's again referring to the direct effects. Total effects, for instance of NAT on GDP $\mathrm{pc}_{\mathrm{p}}$, then consist of the direct effect $\beta_{\text {gdp,nat, }}$ as well as four indirect effects through tourism specialization and tourism 
performance: (1) $\beta_{\text {empts,nat }} *\left[\beta_{\text {gdp,empts }}+\left(\beta_{\text {nig,empts }} * \beta_{\text {gdp,nig }}\right)+\left(\beta_{\text {gvat,empts }} * \beta_{\text {gdp,gvat }}\right)\right]$, (2) $\beta_{\text {gvats,nat }} *\left[\beta_{\text {gdp,gvats }}+\right.$

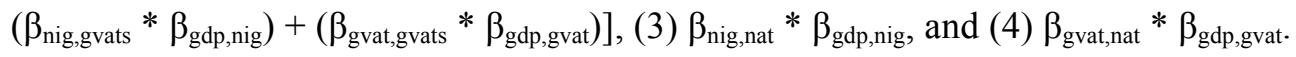

These paths are tested in the AMOS 23.0 package for IBM SPSS, using the Maximum Likelihood (ML) method of parameter estimation. Given the difference in measurement levels, for computation purposes, natural logarithms were applied to the variables related to gross value added by tourism, tourism demand, gross fixed capital formation in tourism, and gross domestic product per capita.

While structural equation modelling allows for the simultaneous estimation of multiple regression equations based on latent factors, thus linking regression analysis with factor analysis, as a result of the nonlatent construction of our model, only the path analysis functionalities are required here. Therefore, Mulaik \& Millsap's (2000) four-step modelling approach, which would require (a) an explanatory factor analysis, (b) a confirmatory measurement model, (c) a relational structural model, and (d) nested models to identify the most parsimonious model, could therefore be reduced to a two-step approach in which only the latter two steps are essential.

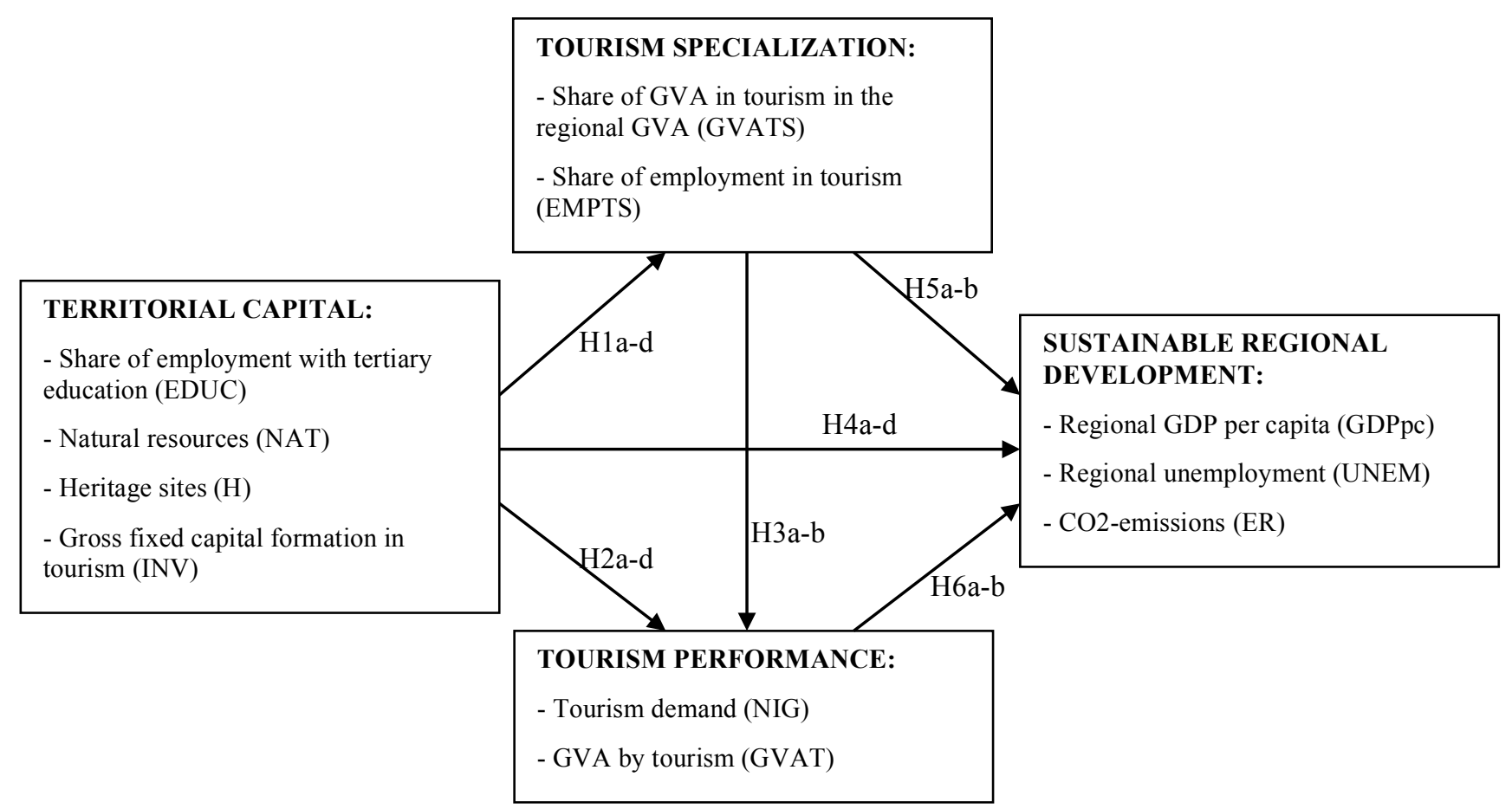

Figure 1: Structure of the work

\section{Results}

Running the theoretical model of Figure 1 leads to satisfactory goodness-of-fit indicators. The chisquare statistic of 6.078 approaches insignificance with a p-value of $.048(\mathrm{Df}=2)$. However, multiple authors (e.g. Fan et al. 2011; Kenny \& McCoach 2003; Schumacker \& Lomax 2004) have noted that the chisquare value is sensitive to sample size, model complexity, and deviation from multivariate normality. Bollen \& Stine (1992) and Yuan \& Bentler (2000) have therefore proposed the modified Bollen-Stine bootstrap as a better-performing chi-square statistic. With a p-value of .085, this test shows an acceptable model fit. Hooper, Coughlan \& Mullen (2008) discuss a range of alternative model fit statistics. With a root- 
mean-square error of approximation (RMSEA) of .090, a comparative fit index (CFI) of .996, a goodness of fit (GFI) of .996, and a standardized root mean square residual (SRMR) of .0231, the various model fit indices give a further indication that the model fits the data to an acceptable degree. Table 2 gives an overview of the relationships between territorial capital, tourism specialization, tourism performance, and sustainable regional development, which were found to be significant by a maximum likelihood estimation.

A series of nested structural models were tested in order to identify the best fitting and most parsimonious model. A total of 182 different models were tested on top of the saturated model after which a Likelihood ratio test was performed, comparing the difference $\mathrm{D}^{2}$ between the $\chi^{2}$-values of the full model and the nested models with the tabled $\chi^{2}$-values for the relevant degrees of freedom. Since all $\chi^{2}$-values of alternative models were significantly higher than the original model, no modification could be accepted on grounds of parsimony (Garson, 2015).

Table 2: Results of the structural equation model

\begin{tabular}{|c|c|}
\hline & $\begin{array}{l}\text { Unstandardized estimates } \\
(S E)\end{array}$ \\
\hline $\begin{array}{l}\text { Employment share with tertiary education } \\
\text { > Share of employment in tourism } \\
\text { > Gross value added by tourism } \\
\text { > Regional GDP per capita } \\
\text { > Regional unemployment }\end{array}$ & $\begin{array}{l}-.045(.022)^{*} \\
.029(.005)^{* * *} \\
.022(.004)^{* * *} \\
.086(.032)^{* *}\end{array}$ \\
\hline $\begin{array}{l}\text { Natural resources } \\
>\text { Share of GVA in tourism in regional GVA } \\
>\text { Share of employment in tourism } \\
>\text { Gross value added by tourism } \\
>\text { Regional unemployment }\end{array}$ & $\begin{array}{l}.093(.041)^{*} \\
.121(.026)^{* * *} \\
-.019(.005)^{* * *} \\
.158(.028)^{* * *}\end{array}$ \\
\hline $\begin{array}{l}\text { Heritage sites } \\
>\text { Gross value added by tourism } \\
>\text { Tourism demand } \\
>\text { Regional unemployment }\end{array}$ & $\begin{array}{l}.196(.029)^{* * *} \\
.224(.035)^{* * *} \\
.795(.167)^{* * *}\end{array}$ \\
\hline $\begin{array}{l}\text { Gross fixed capital formation in tourism } \\
>\text { Gross value added by tourism } \\
>\text { Tourism demand }\end{array}$ & $\begin{array}{l}.402(.046)^{* * *} \\
.280(.054)^{* * *}\end{array}$ \\
\hline $\begin{array}{l}\text { Share of GVA in tourism in regional GVA } \\
>\text { Gross value added by tourism }\end{array}$ & $.030(.010)^{* *}$ \\
\hline $\begin{array}{l}\text { Share of employment in tourism } \\
>\text { Gross value added by tourism } \\
>\text { Tourism demand } \\
>\text { Regional unemployment } \\
>\text { CO2-emissions }\end{array}$ & $\begin{array}{l}-.031(.016)^{*} \\
.062(.019)^{* *} \\
.550(.087)^{* * *} \\
-.024(.163)^{* *}\end{array}$ \\
\hline $\begin{array}{l}\text { Tourism demand } \\
>\text { Regional GDP per capita } \\
>\text { Regional unemployment }\end{array}$ & $\begin{array}{l}.121(.044)^{* *} \\
-1.281(.359) * * *\end{array}$ \\
\hline
\end{tabular}




\begin{tabular}{ll}
\hline Gross value added by tourism & \\
$>$ Regional GDP per capita & $.227(.053)^{* * *}$ \\
$>$ CO2-emissions & $13.750(.820)^{* * *}$ \\
& \\
Regional GDP per capita & \\
$>$ Regional unemployment & $-2.468(.506)^{* * *}$ \\
$>$ CO2-emissions & $-9.693(.949)^{* * *}$ \\
\hline
\end{tabular}

Results indicate that a higher level of tertiary education negatively influences the number of people that are employed in the tourism sector (-.045). On the other hand, gross value added of tourism (.029), is positively related to higher shares of tertiary educated workforce. Concerning material assets, it is noticeable that while a higher level of protected areas is related to a lower gross value added by tourism (-.019), the reverse is true for number of heritage sites (.196) and gross fixed capital formation in tourism (.402). Both heritage sites and tourism capital investments are furthermore related to a higher level of tourism demand (.224 and .280 respectively). Natural resources are the only territorial capital assets that directly influence tourism specialization, being positively related to both the share of tourism gross value added in the total regional gross value added (.093) and the share of tourism employment (.121). Finally, there is a significant link between tourism specialization and tourism performance, with the share of gross value added of tourism within the region being positively related to total tourism gross value added (.030). Similarly, the share of tourism employment is significantly positively related to tourism demand (.062). On the other hand, the higher the share of tourism employment in total employment, the lower the absolute gross value added in tourism seems to be $(-.031)$.

Looking closer into the effects of territorial capital, tourism specialisation, and tourism performance on indicators of sustainable regional development, we can see that regional gross domestic product per capita is driven by a well-educated workforce (.022), a higher number of overnight stays in tourist accommodations (.121) and a larger gross value added in tourism (.227). This further influences the two other factors of sustainable regional development, since a larger gross domestic product per capita is related to lower $\mathrm{CO} 2-$ emissions (-9.693) and a decline in regional unemployment (-2.468). Regional unemployment is furthermore related to a number of other factors. A rising tourism demand is advantageous to combat unemployment (1.281), while, a higher degree of tertiary educated people in the workforce, as well as a larger share of employment within the tourism sector, both increase regional unemployment numbers (.086 and .550 respectively). Similarly, territorial capital that is more related to natural resource protection and heritage site, has a negative effect on employment (.158 and .795 respectively). In terms of improving environmental conditions, a higher share of tourism employment is associated with a lower amount of CO2-emission (.424), however, an increase of absolute gross value added in tourism significantly correlates with a rise in regional $\mathrm{CO} 2$-emissions (13.750).

\section{Discussion}

The results of this analysis can be systematized by taking into consideration the expected impacts of tourism dynamics on the Millennium Development goals, as mentioned by UNWTO (2015), mostly in terms 
of the contribution of natural or cultural resources, innovation dynamics and tourism activities to an inclusive (regional) process of economic growth, based on sustainable patterns of consumption and production. This discussion can be framed within the "smart specialization" approach to regional development currently adopted in European regions, thereby offering important policy and managerial implications.

One factor of major concern for the regions where tourism plays a more prominent role with the regional economic structure is the confirmation of the results obtained by Milio (2014), suggesting that regions more specialized in tourism and construction tend to register slower processes of recovery after the international financial crisis started in 2007. In fact, our analysis (for 2011) reveals that higher importance of tourism services within the regional employment are positively correlated with higher levels of unemployment. In this sense, tourism dynamics are not contributing to a process of inclusive growth, as these regions seem to be experiencing high levels of unemployment.

This problem is emphasized by the relations identified in our model between the importance of tourism for regional employment and high levels of tourism demand but relatively low value added by tourism activities. These results clearly suggest that, for these regions, tourism supply is mostly based on products and services oriented to mass consumption, with low value added. This can also be related to an excessive (and unsustainable) use of resources, which seems to be confirmed by the negative relation identified between the endowment of natural resources and the gross value added in tourism. In fact, this seems to be the case of most of the coastal Southern European regions, with high levels of tourism demand and large parts of their territories included in the Natura 2000 network (as suggested by Romão, 2015), which is confirmed by the positive relation found between the abundance of natural resources and the levels of specialization in tourism (both in terms of employment and gross value added) and by the correlation between natural resources and high levels of unemployment.

These relationships indicate that the potential resource-based competitive advantage is insufficiently operationalized within these regions. It mirrors observations made within the European Union's Smart Specialisation Platform (S3P) about the untapped potential of heritage resources as engine for innovation and growth (Pertoldi, 2016). A smart specialization strategy prioritizing the tourism sector requires additional spatial development through linkage with other relevant economic sectors, potentially based on innovation strategies, digitization and imaging (Borseková et al., 2016), reinforced by new forms of territorial design, which can contribute to a provision of tourism services with higher value added and based on the local endowment related to natural and cultural elements.

On the other hand, the level of education seems to exert a very high impact on regional growth, while having different types of correlation with different aspects of tourism dynamics. Regions where specialization in tourism is higher (when measured by the weight of this sector within regional employment) seem to be those where the workforce is less educated. On the other hand, high levels of education appear to be correlated with high levels of value added by tourism services. These different types of relations clearly reveal the heterogeneity of European regions regarding tourism dynamics and its impacts on the economy, which seem to depend on a broader set of variables, as it was assumed in this study. Again, these results suggest that Southern European regions are those where these problems are more relevant, as their 
population reveals lower levels of education when compared with Central of Northern European regions. In that sense, regions more specialized in tourism seem to be less prepared for the integration of knowledge and technology into their economic systems, as it is proposed by the smart development approaches.

If the importance of tourism seems to be correlated with the existence of high levels of unemployment and education, this also implies a negative relation with economic growth, which is (as expected) positively correlated with both variables. Nevertheless, there is a positive aspect in terms of the environmental sustainability of the regions more specialized in tourism, as low CO2-emissions seem to be positively related with a high importance of tourism for regional employment. Even if this can be related to the low development of other economic activities (like manufacturers with impacts on the atmosphere), it seems to be in accordance with the principles of sustainable development.

\section{Conclusion}

This study analyses the link between the utilization of natural and cultural resources, along with other immaterial characteristics of the territorial capital of heterogeneous European regions, defining their innovation abilities characteristic of the smart development processes, in relation to tourism specialization and performance, aiming at the identification of the impacts of this global set of factors on sustainable development of European regions. The effects of tourism activities on regional sustainable development were analysed taking into consideration the well-established triple bottom-line, leading to some relevant implications in terms of production systems, resource allocation or territorial design. In that sense, our discussion is particularly oriented to the implications for the less developed European regions, which are generally those where tourism plays a more prominent role, analysing the spatial imbalances within European regions. A structural equation model provided the tool for an inclusive analysis of these interrelations.

Combining these results, it seems plausible to suggest that different regional patterns of tourism dynamics coexist in contemporary European regions and that, for those where tourism assumes larger socioeconomic importance, the contribution of tourism to the achievement of the Millennium Goals related to sustainable development is relatively poor. Regions highly specialized in tourism are particularly endowed with natural resources, but tourism activities seem to be based on large scale and low value-added products and services, with reduced socio-economic impacts, leading to high levels of unemployment. Both in terms of the utilization of environmental assets and the mobilization of resources and knowledge for innovative activities with high value added, the results obtained suggest that specialization in tourism does not contribute to reduce the development gap currently existing among European regions. Consequently, a territorial redesign oriented to the valuation and preservation of specific natural and cultural factors, along with a reorganization of the regional economic systems - and in particular the production of tourism services in their relation with the territorial resources - seems to be crucial for the less developed European regions.

Keeping in mind the relatively good performance of these regions in terms of $\mathrm{CO} 2$-emissions, it seems important for their development to increase the value added in tourism, by reinforcing the linkages with other (related) economic sectors with relevance in the regional context. In this sense, the diversification of 
economic activities (e.g., by developing related industrial activities), should take into consideration the importance of maintaining low levels of $\mathrm{CO} 2$-emissions, by promoting environmental friendly processes of industrial development. In this sense, technological and industrial developments oriented to the energy or transport sector, promoting savings on energy consumption and production of energy based on renewable sources could be particularly interesting for these regions, with a high potential to be linked to tourism services. Additionally, low emissions, energy savings, and eco-friendly mobility systems can clearly contribute to the image of these territories as sustainable tourism destinations.

In this context, the strategy of product development and differentiation proposed by Benur and Bramwell (2015), aiming at diversifying the tourism supply by adding secondary new products and services to the core elements of the regional supply, seems to be relevant in order to increase the value added by tourism. Also, as it is proposed by the "smart tourism" or the "smart specialization" approaches, the development of information and communication services can have relevant impacts in regions where tourism plays a prominent role, as tourists permanently need information related to mobility, facilities, services or local resources. In this sense, these technologies can also enhance the relations between tourism and connected sectors, exploring the related variety of economic activities in the region (Neffke et al., 2009).

Nevertheless, these authors also claim that a process of regional specialization based on a small number of related sectors exposes the region to the fluctuations of demand in those specific activities. In that sense and considering that tourism demand is relatively volatile, highly elastic regarding fluctuation in prices and revenues and very sensitive to external elements (conflicts, security, safety or weather conditions) - a strategic development process based on different types of related sectors (not only around the tourism cluster) seems to be highly recommended, if these regions aim at reaching higher levels of economic development and social equality. On the other, it was also observed that the spatial unbalances in terms of socio-economic development in European regions appear to be clearly related to their performance in terms of innovation dynamics or labour qualifications, while regions with higher specialization in tourism show a relatively weak performance in these aspects. In this sense, the tourism sector does not seem to promote a high engagement with the smart development processes, with relatively low utilization of knowledge, innovation and qualified labour force.

Although the results of this analysis are clearly relevant from a statistical point of view, while allowing to address important questions related to the relation between tourism dynamics, territorial resources, and sustainable development, further research is required in order to identify with higher precision different regional patterns of evolution and possible changes over time. Also, the evaluation of environmental impacts requires more precise information, as the data used in this work related to $\mathrm{CO} 2$-emissions were not collected at regional level, but based on national information. Furthermore, spatial impacts of tourism on local ecosystems are more complex than a measurement of $\mathrm{CO} 2$-emissions allows for. Considering the importance of these problems in contemporary societies and in the European context, this can surely be addressed in the near future 


\section{References:}

Adamou, A., \& S. Clerides (2009). Prospects and limits of Tourism-Led Growth: the international evidence. The Rimini Centre for Economic Analysis Working Papers 41-09. Rimini.

Alexiadis, S. (2017). Territorial cohesion and prospects for sustainable development: a co-integration analysis. Habitat International, in press, 1-9.

Al Haija, A.A. (2011). Jordan: Tourism and conflict with local communities (2011). Habitat International, 35,: 93-100.

Antonakakis, N., Dragouni M., \& Filis, G. (2015). How strong is the linkage between tourism and economic growth in Europe?. Economic Modelling, 44, 142-155.

Benur, A.M. \& Bramwell, B. (2015). Tourism product development and product diversification in destinations, Tourism Management, 50, 213-224.

Bertacchini, E. \& Segre, G. (2016) Culture, sustainable development and social quality: A paradigm shift in the economic analysis of cultural production and heritage conservation. City, Culture and Society, 7, 6970.

Binkhorst, E. \& Den Dekker, T. (2009). Agenda for Co-Creation Tourism Experience Research. Journal of Hospitality Marketing \& Management, 18(2-3), 311-327.

Boes, K., Buhalis, D., \& Inversini, A. (2016) Smart tourism destinations: ecosystems for tourism destination competitiveness, International Journal of Tourism Cities, 2(2): 108-124.

Bollen, K. A., \& Stine, R. A. (1992). Bootstrapping goodness-of-fit measures in structural equation models. Sociological Methods and Research, 21, 205-229.

Borseková, K., Vaňová, A., \& Vitálišová, K. (2016) Smart Specialization for Smart Spatial Development: Innovative Strategies for Building Competitive Advantages in Tourism in Slovakia. Socio-Economic Planning Sciences, in press, 1-12.

Boschma, R. (2016). Smart Specialisation and Regional Innovation Policy. Welsh Economic Review 24, 17.

Buhalis, D. (1999) Limits of tourism development in peripheral destinations: problems and challenges, Tourism Management, 20, 183-185.

Butler, R.W. (1999). Sustainable tourism: A state-of-the-art review. Tourism Geographies, 1(1), 7-25.

Capello, R., Caragliu, A., \& Nijkamp, P. (2011). Territorial Capital and Regional Growth: Increasing Returns in Knowledge Use. Tijdschrift voor Economische en Sociale Geografie 102(4), 385-405.

Caragliu, A., \& Del Bo, C. (2012) Smartness and European urban performance: assessing the local impacts of smart urban attributes. Innovation: The European Journal of Social Science Research, 25(2), 175 190.Caragliu, A., Del Bo, C. \& Nijkamp, P. (2011) Smart Cities in Europe. The Journal of Urban Technology, 18(2), 65-82.

Capó, J., Font, A., \& Nadal, J. (2007). Dutch Disease in Tourism Economies: Evidence from the Balearics and the Canary Islands. Journal of Sustainable Tourism 15(6), 615-627.

Chen, C., \& Chiou-Wei, S. (2009). Tourism expansion, tourism uncertainty and economic growth: new evidence from Taiwan and Korea. Tourism Management 30(6), 812-818. 
Chou, M. (2013). Does tourism development promote economic growth in transition countries? A panel data analysis. Economic Modelling 33, 226-232.

Cortes-Jimenez, I., \& Pulina, M. (2010). Inbound tourism and long-run economic growth. Current Issues in Tourism 13(1), 61-74.

Directorate-General for Regional and Urban Policy (2016). Regional Policy. Retrieved April 3, 2017, from http://ec.europa.eu/regional_policy/en/.

Dritsakis, N. (2004). Tourism as a long-run economic growth factor: an empirical investigation for Greece using causality analysis. Tourism Economics, 10(3), 305-316.

Dritsakis, N. (2012). Tourism development and economic growth in seven Mediterranean countries: a panel data approach. Tourism Economics, 18(4), 801-816.

Fan, X., Thompson, B., \& Wang, L. (2011). Effects of sample size, estimation methods, and model specification on structural equation modeling fit indexes. Structural Equation Modeling: A Multidisciplinary Journal, 6(1), 56-83.

Foray, D., Goddard, J., Beldarrain, M., Landabaso, M, McCann, P., Morgan, K., Nauwelaers, C., \& OrtegaArgilés, R. (2012). Guide to Research and Innovation Strategies for Smart Specialisation. Brussels: S3PEuropean Union.

França, C.S., Broman, G., Robèrt, K., Basile, G. \& Trygg, L. (2017). An approach to business model innovation and design for strategic sustainable development. Journal of Cleaner Production, 140, 155166.

Garson, G.D. (2015). Structural Equation Modeling. Asheboro, NC: Statistical Associates Publishers.

Hall, R. (1993). A framework linking intangible resources and capabilities to sustainable competitive advantage. Strategic Management Journal, 14(8), 607-618.

Halme, M. \& Korpela, M. (2014), Responsible Innovation Toward Sustainable Development in Small and Medium-Sized Enterprises: a Resource Perspective. Business Strategy and the Environment, 23, 547566.

Hassan, S. (2000). Determinants of market competitiveness in an environmentally sustainable tourism industry, Journal of Travel Research, 38,3, 239-245.

Kenny, D.A., \& McCoach, B. D. (2003). Effect of the number of variables on measures of fit in Structural Equation Modeling. Structural Equation Modeling: A Multidisciplinary Journal, 10(3), 333-351.

Kim, J. \& Fesenmaier, D.R. (2015). Measuring Emotions in Real Time: Implications for Tourism Experience Design. Journal of Travel Research, 54(4), 419 - 429.

Kourtit K., Nijkamp P. \& Arribas D. (2012). Smart cities in perspective - a comparative European study by means of self- organizing maps. Innovation: The European Journal of Social Science Research, 25(2), 229-246.

Kozak, M. (1999). Destination Competitiveness Measurement: Analysis of Effective Factors and Indicators, European Regional Science Association Conference Papers, Dublin.

Lee, C., \& C. Chang (2008). Tourism development and economic growth: a closer look at panels. Tourism Management 29(1), 180-192. 
Liu, J., Nijkamp, P., \& Derong, L. (2017). Urban-rural Imbalance and Tourism-Led Growth in China. Annals of Tourism Research, 64, 24-36.

Maes, J. \& Jacobs, S. (2017). Nature-Based Solutions for Europe's Sustainable Development. Conservation Letters, 10(1), 121-124.

McCann, P. \& Ortega-Argilés, R. (2015). Smart Specialization, Regional Growth and Applications to European Union Cohesion Policy. Regional Studies, (49), 1291-1302.

Miller, G., \& Twining-Ward, L. (2005). Monitoring for a sustainable tourism transition: the challenge of developing and using indicators. Oxfordshire: CABI Publishing.

Milio, S. (2014), Impact of the Economic Crisis on Social, Economic and Territorial Cohesion of the European Union, Vol. 1. Brussels: Directorate-General for Internal Policies, Policy Department B (Structural and Cohesion Policies).

Modica, M., \& A. Reggiani (2014). Spatial Economic Resilience: Overview and Perspectives. Networks and Spatial Economics 15(2), 211-233.

Mulaik, S.A. \& Millsap, R.E. (2000). Doing the four-step right. Structural Equation Modeling, 7, 36-73.

Neffke, F., Henning, M., \& Boschma, R. (2009). How do regions diversify over time? Industry relatedness and the development of new growth paths in regions. Papers in Evolutionary Economic Geography, 09.16.

Nowak, J., Sahli, M., \& Cortés-Jiménez, I. (2007). Tourism, capital good imports and economic growth: theory and evidence for Spain. Tourism Economics 13(4), 515-536.

Pablo-Romero, M., \& J.A. Molina (2013). Tourism and economic growth: A review of empirical literature. Tourism Management Perspectives 8, 28-41.

Page, S. J., \& Dowling, R. K. (2002). Ecotourism. Harlow, Prentice Hall.

Pertoldi, M. (2016, November). Smart Specialisation and Cultural Heritage: an overview. In R. Bellotti (Chair), Smart Specialisation and Cultural Heritage: An Engine for Innovation and Growth. Symposium conducted at the meeting of the S3 Platform (Joint Research Centre, European Union), Roma, Italy.

Poon, A (1994). The 'new tourism' revolution, Tourism Management, 15(2), 91-92.

Redclift, M. \& Woodgate, G. (2013). Sustainable Development and Nature: The Social and The Material. Sustainable Development, 21, 92-100.

Ritchie, J., \& Crouch, G. (2003) The competitive destination: A sustainable tourism perspective, Oxfordshire: CABI and CABI International.

Romão, J. (2015). Culture or Nature: a space-time analysis on the determinants of tourism demand in European regions. Discussion Papers on Spatial and Organisational Dynamics, 15-3.

Romão, J., Guerreiro, J., \& Rodrigues, P.M.M. (2016. Tourism growth and regional resilience: The 'beach disease' and the consequences of the global crisis of 2007. Tourism Economics, 22(4), 699-714.

Saarinen, J. \& Rogerson, C.M. (2014). Tourism and the Millennium Development Goals: perspectives beyond 2015. Tourism Geographies, 16(1), 23-30. 
Shubert, S., \& J. Brida (2011). Dynamic Model of Economic Growth in a Small Tourism Driven Economy. In A. Matias, P. Nijkamp \& M. Sarmento, eds., Tourism Economics - Impact Analysis, (pp: 149-168). Berlin: Springer-Verlag.

Schumacker, R. E., \& Lomax, R. G. (1996). A Beginner's Guide to Structural Equation Modeling. Mahwah, NJ: Lawrence Erlbaum Associates.

Serbanica, C., \& Constantin, D.-L. (2017). Sustainable cities in central and eastern European countries. Moving towards smart specialization. Habitat International, in press, 1-9.

Sheng, L. \& Tsui, Y. (2009). A general equilibrium approach to tourism and welfare: The case of Macao. Habitat International, 33, 419-424.

Tang, C., \& S. Jang (2009). The tourism-economy causality in the United States: a sub-industry level examination. Tourism Management 30(4), 553-558.

United Nations (2015). Transforming our world: the 2030 Agenda for Sustainable Development. A/RES/70/1, Resolution adopted by the General Assembly on 25 September 2015. New York.

Weaver, D. (2006) Sustainable Tourism: Theory and Practice. Oxford, Elsevier.

Weaver, D. (2011). Can sustainable tourism survive climate change?. Journal of Sustainable Tourism, 19(1), 5-15.

Williams, P., \& Ponsford, I. (2009), Confronting tourism's environmental paradox: Transitioning for sustainable tourism. Futures, 41, 396-404.

World Tourism Organization (2010). Manual on Tourism and Poverty Alleviation, Practical Steps for Destinations. Madrid, UNWTO.

World Tourism Organization (2015). Tourism and the Sustainable Development Goals. Madrid, UNWTO.

World Tourism Organization (2017). Tourism Highlights 2016 Edition. Madrid, UNWTO.

Wu,S.R., Fan, P. \& Chen, J. (2016). Incorporating Culture Into Sustainable Development: A Cultural Sustainability Index Framework for Green Buildings. Sustainable Development, 24, 64-76.

Yuan, K.H., \& Bentler, P. M. (2000). Three likelihood-based methods for mean and covariance structure analysis with nonnormal missing data. In M. Becker \& M. Sobel (Eds.), Sociological methodology 2000 (pp: 165-200).. Maiden, MA: Blackwell.

Zhang, X., Zhou, L., Wu, Y., Skitmore, M. \& Deng, Z. (2015). Resolving the conflicts of sustainable world heritage landscapes in cities: Fully open or limited access for visitors? Habitat International, 46, 91-100.

Zhao, W., \& Ritchie, J. (2007). Tourism and Poverty Alleviation: An Integrative Research Framework. Current Issues in Tourism, 10(2-3), 119-143. 
Annex: Data and variables

The data used in this study are geographically represented in the following Figures. In all the maps, the data was organized in classes based on quintiles of the distribution, therefore including a similar number of observations. Darker colors represent higher values for the variable under analysis. In order to have a more efficient utilization of space, the boxed islands (The Azores, Madeira and Canary Islands on the South West side; and Cyprus in the South East) were repositioned for these representations.

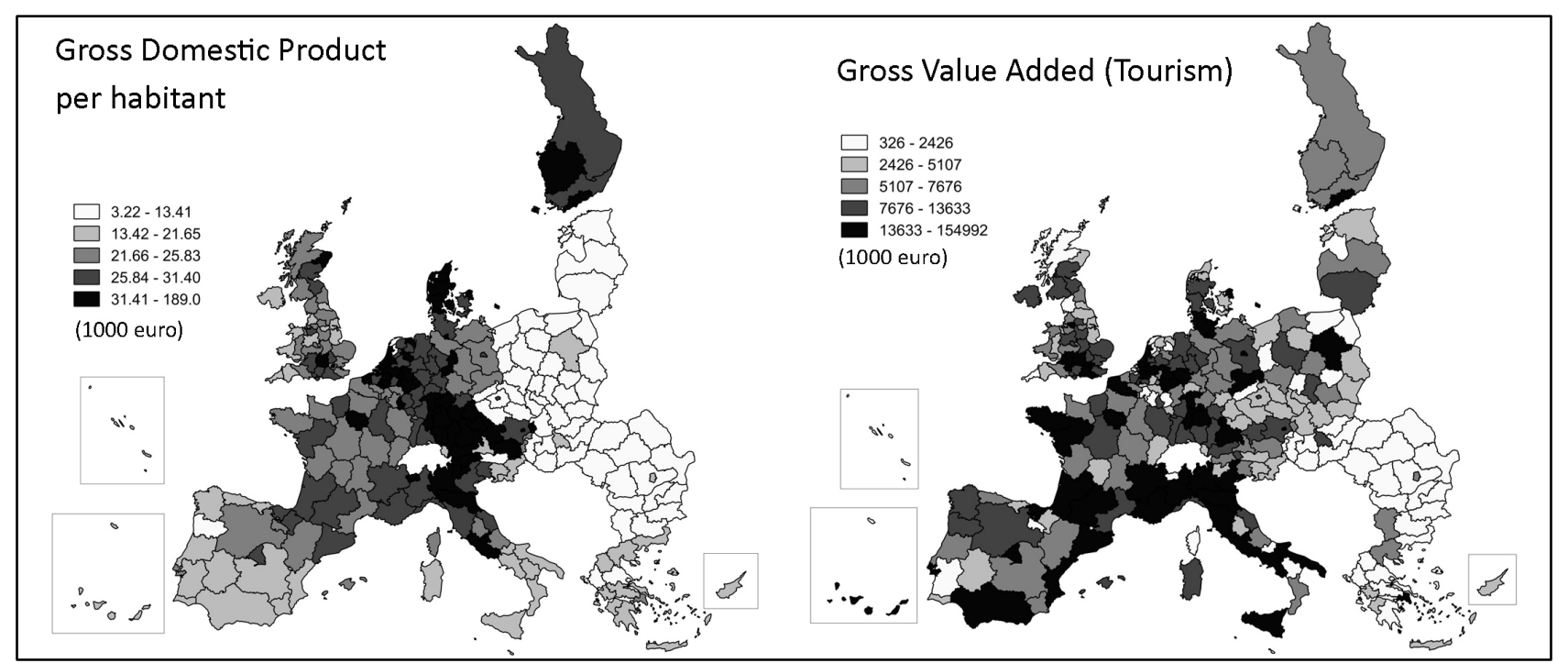

Figure A1: Gross domestic product per habitant and gross value added by tourism

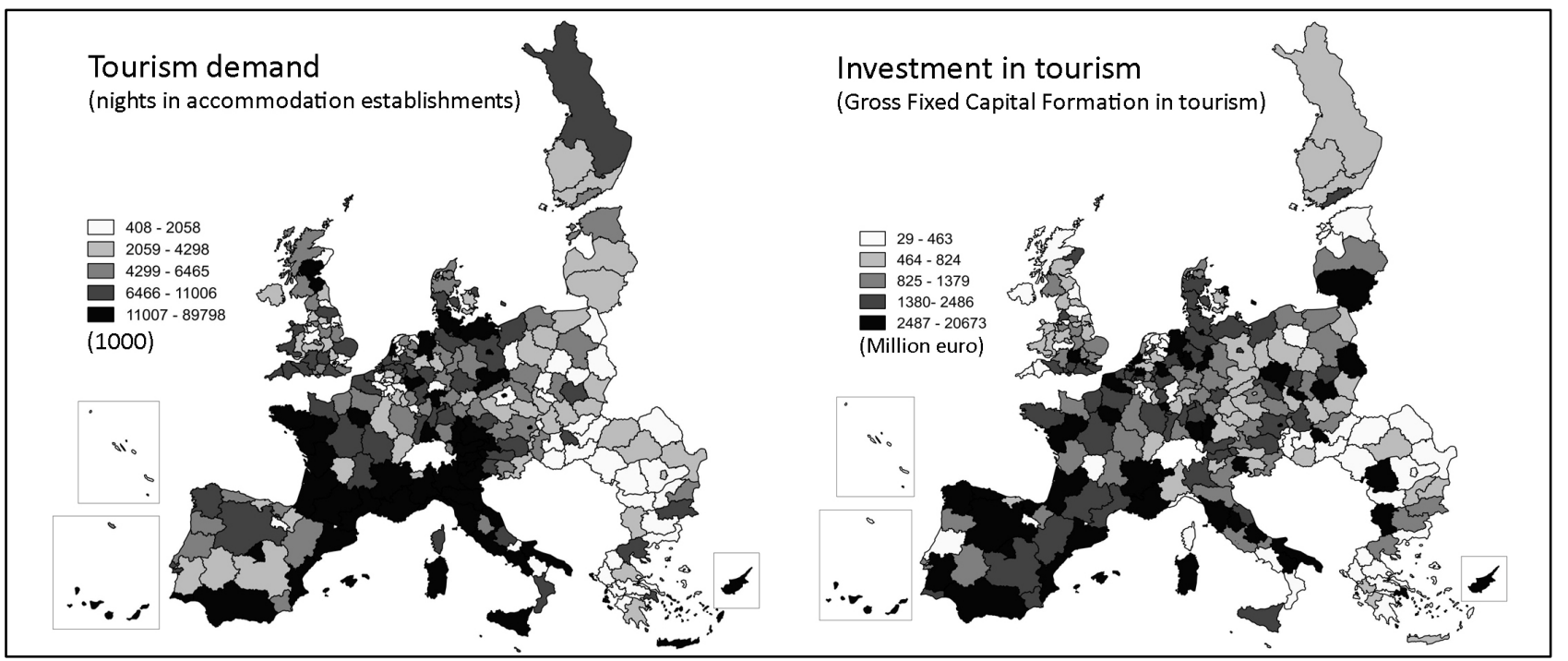

Figure A2: Regional tourism dynamics 


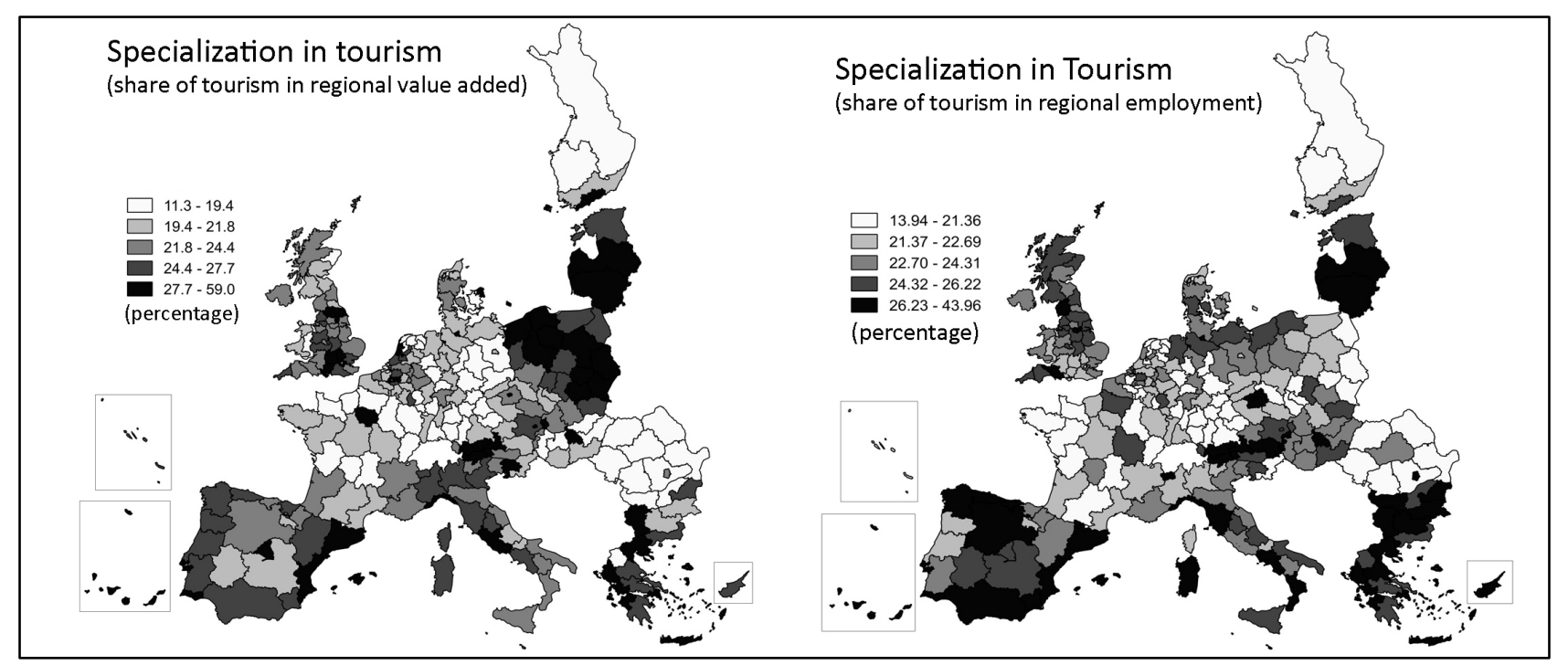

Figure A3: Specialization in tourism

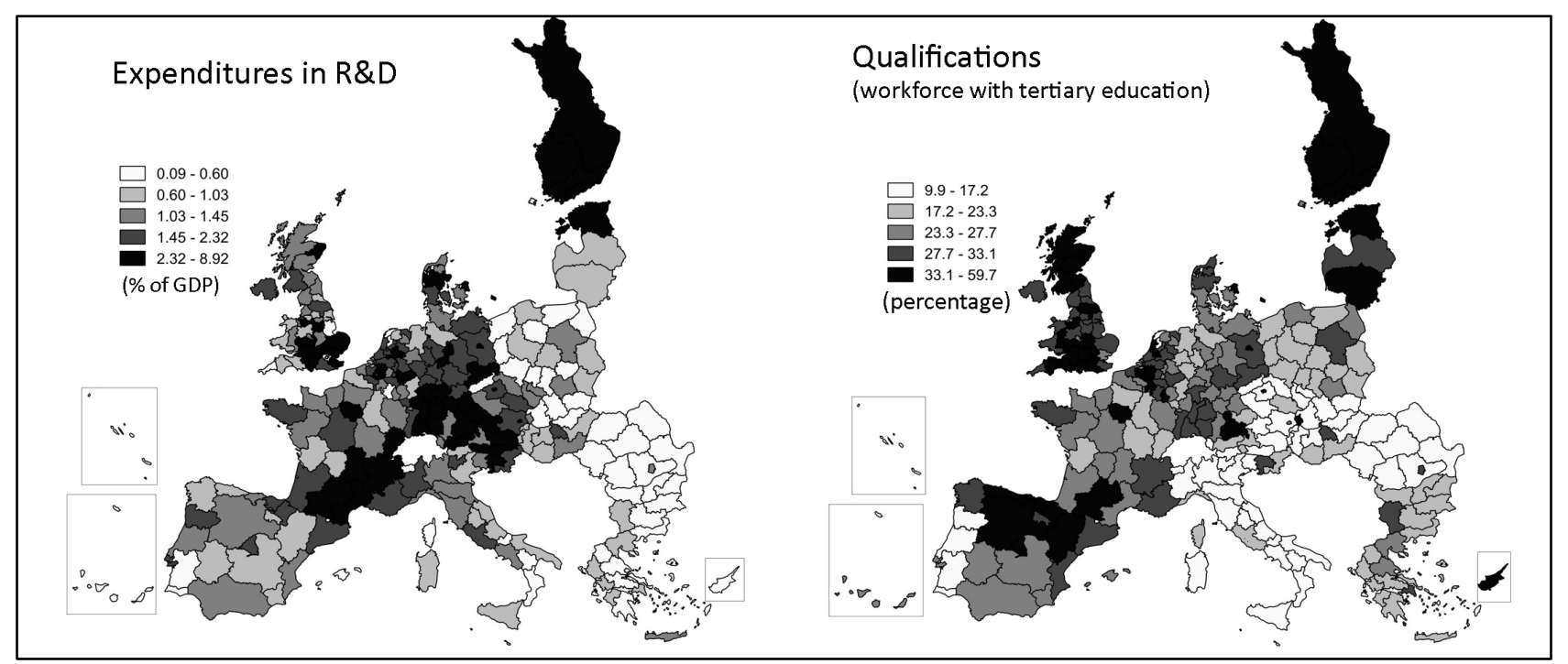

Figure A4: Territorial immaterial resources

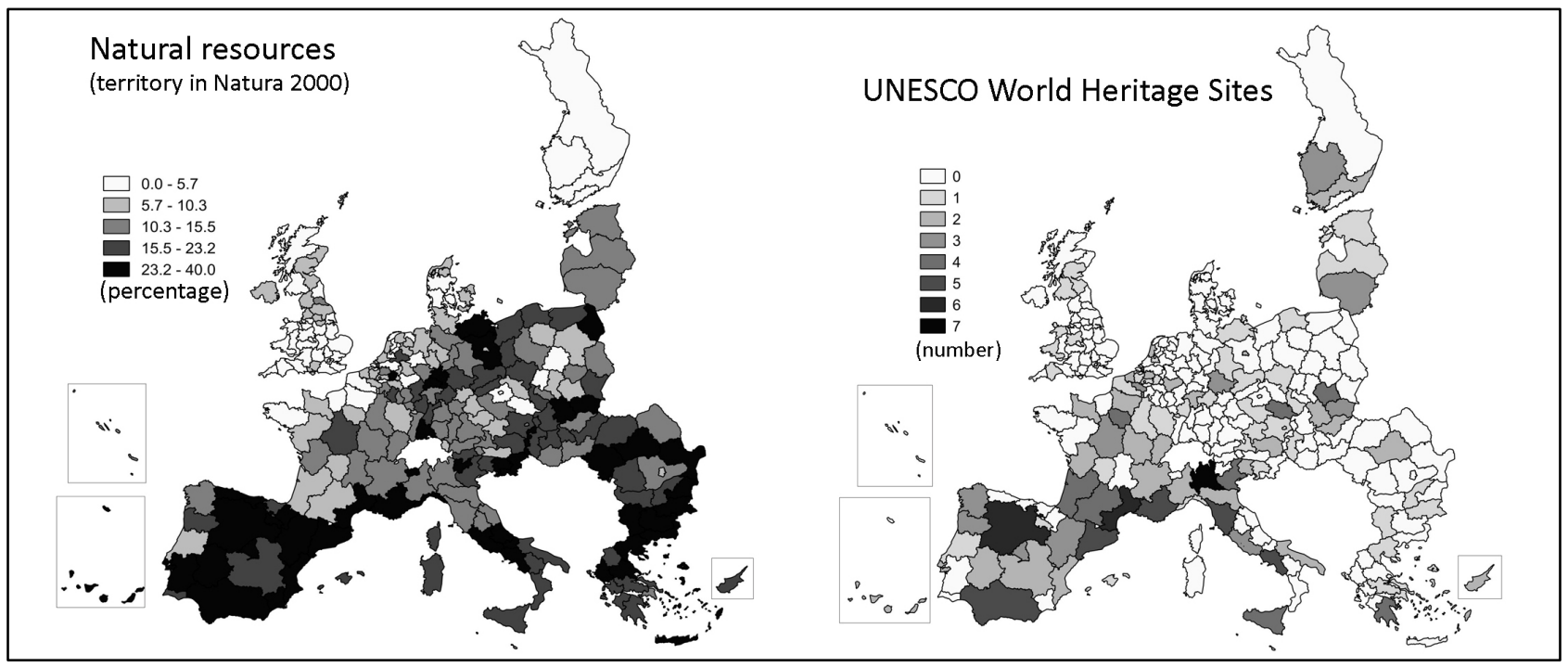

Figure A5: Territorial natural and cultural resources 


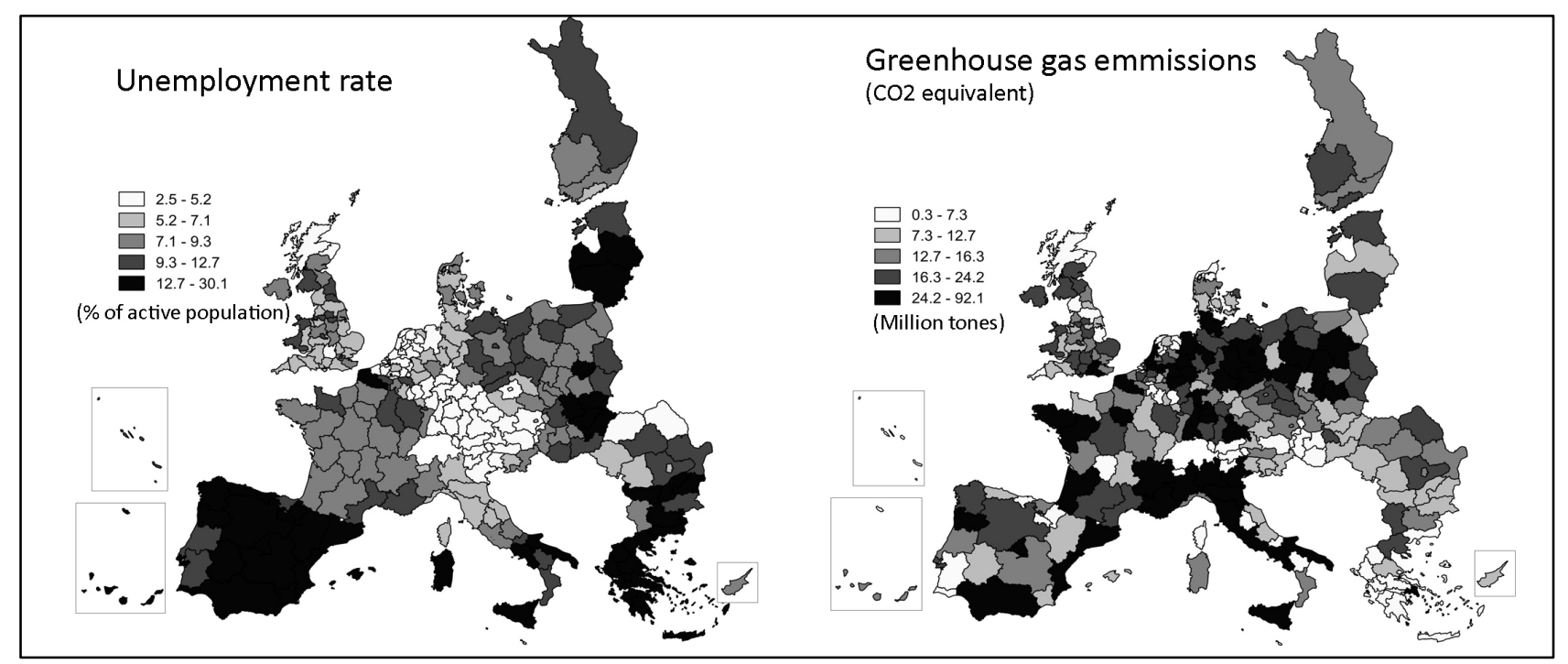

Figure A6: Environmental and social development indicators 